\title{
The clinical effective dose of alfentanil for suppressing cough during emergence from desflurane anesthesia
}

\author{
Mi Geum Lee, Young Jin Chang, Jong Min Park, and Hee-Yeon Park \\ Department of Anesthesiology and Pain Medicine, Gil Medical Center, Gachon University of Medicine and Science, Incheon, Korea
}

Background: The administration of short-acting opioids before emergence is useful for preventing emergence cough induced by an endotracheal tube. This study examined the clinically effective dose of alfentanil for suppressing cough during emergence from desflurane anesthesia.

Methods: Twenty-nine adult patients undergoing elective oral surgery were enrolled in this study. During emergence from anesthesia, the patients received alfentanil diluted in $10 \mathrm{ml}$ normal saline when the end-tidal vol\% of desflurane decreased to $3 \%$. The initial alfentanil dose was $16 \mu \mathrm{g} / \mathrm{kg}$. The alfentanil dose for consecutive patients, determined by Dixon's up-and-down method, increased or decreased by $2 \mu \mathrm{g} / \mathrm{kg}$ according to a previous patient's result.

Results: The $50 \%$ effective dose $\left(\mathrm{ED}_{50}\right)$ of alfentanil for suppressing cough during emergence from desflurane anaesthesia was $9.3 \pm 1.5 \mu \mathrm{g} / \mathrm{kg}$ according to Dixon's up-and-down method. Isotonic regression revealed an $\mathrm{ED}_{50}$ and $\mathrm{ED}_{95}(95 \%$ confidence interval) of alfentanil $10.0 \mu \mathrm{g} / \mathrm{kg}(6.8-13.2 \mu \mathrm{g} / \mathrm{kg})$ and $14.0 \mu \mathrm{g} / \mathrm{kg}(7.7-19.4 \mu \mathrm{g} / \mathrm{kg})$, respectively.

Conclusions: The $\mathrm{ED}_{95}$ of alfentanil for suppressing emergence cough was $14.0 \mu \mathrm{g} / \mathrm{kg}$. A single bolus administration of alfentanil during emergence from anesthesia was useful for suppressing emergence cough. (Korean J Anesthesiol 2011; 61: 292-296)

Key Words: Alfentanil, Dixon's up-and-down method, Emergence cough.

Received: March 11, 2011. Revised: 1st, April 13, 2011; 2nd, April 18, 2011; 3rd, April 21, 2011. Accepted: April $21,2011$.

Corresponding author: Hee-Yeon Park, M.D., Department of Anesthesiology and Pain Medicine , Gil Medical Center, Gachon University of Medicine and Science, 1198, Guwol-dong, Namdong-gu, Incheon 405-760, Korea. Tel: 82-32-460-3637, Fax: 82-32-469-6319, E-mail: yao77@ naver.com

(c) This is an open-access article distributed under the terms of the Creative Commons Attribution Non-Commercial License (http:// creativecommons.org/licenses/by-nc/3.0/), which permits unrestricted non-commercial use, distribution, and reproduction in any medium, provided the original work is properly cited. 


\section{Introduction}

Endotracheal tube-induced coughing during emergence from general anesthesia is a common phenomenon with a reported incidence of 38-96\% [1-3]. Emergence cough is associated with an increase in heart rate, blood pressure, intracranial, intraocular, and intra-abdominal pressure. These adverse effects can result in coronary ischemia, arrhythmia or wound dehiscence [4-6]. Several techniques or drugs have been investigated to prevent emergence cough, such as deep extubation [7], a change to laryngeal mask during emergence [8], topical or intracuff lidocaine application $[9,10]$ and the administration of dexmedetomidine [11] or short-acting opioids [12-14]. The beneficial effects of short-acting opioids, such as alfentanil or remifentanil, for suppressing cough during emergence have been reported. However, there is no data on the optimal dose of alfentanil to prevent cough during emergence. This study examined the clinically effective singledose of alfentanil for suppressing cough during emergence from desflurane anesthesia.

\section{Materials and Methods}

This study was approved by the institutional review board and written informed consent was obtained from the subjects. ASA I-II adult patients undergoing elective oral surgical procedures were enrolled in this study. The exclusion criteria included treatment with antitussives or angiotensin converting enzyme inhibitor, a history of chronic cough, asthma or recent respiratory tract infections. Obese patients (body mass index (BMI) $>30 \mathrm{~kg} / \mathrm{m}^{2}$ ) and patients with predicted difficult intubation were also excluded.

Thirty minutes before the induction of anesthesia, all patients were pre-medicated with intramuscular glycopyrrolate 0.2 $\mathrm{mg}$ and midazolam $2 \mathrm{mg}$. Upon arrival at the operating room, routine anesthesia monitoring including ECG, pulse oximetry, non-invasive arterial pressure, side-stream capnography were applied. Anesthesia was induced with alfentanil $10 \mu \mathrm{g} / \mathrm{kg}$ and propofol $2 \mathrm{mg} / \mathrm{kg}$, intravenously. Rocuronium $0.8 \mathrm{mg} / \mathrm{kg}$ was injected intravenously to facilitate nasotracheal intubation. Reinforced tubes were used with $7.0 \mathrm{~mm}$ ID and $6.5 \mathrm{~mm}$ ID for men and women, respectively. The pressure of the tracheal cuff was maintained at $30 \mathrm{~cm} \mathrm{H}_{2} \mathrm{O}$ throughout the procedure. After induction, dexamethasone $5 \mathrm{mg}$ was administered intravenously. Anesthesia was maintained with desflurane 4-7 vol\% in $50 \% \mathrm{~N}_{2} \mathrm{O} / \mathrm{O}_{2}$ mixture. No additional opioid was administered during surgery. All patients received ketorolac 30 $\mathrm{mg}$ and metoclopromide $10 \mathrm{mg}$ intravenously $30 \mathrm{~min}$ before the end of surgery. Neuromuscular blocking was reversed by pyridostigmine and glycopyrrolate $5 \mathrm{~min}$ before the end of surgery and then the administering gas concentration was gradually decreased. Alfentanil diluted in $10 \mathrm{ml}$ normal saline was injected slowly for $30 \mathrm{~s}$ when the end-tidal vol\% of desflurane was decreased to $3 \%$. After surgery when the drapes were removed, the pharynx was suctioned gently, the vaporizer of desflurane was turned off and fresh gas flow was increased to $6 \mathrm{~L} / \mathrm{min}$ in $100 \%$ oxygen. During the emergence phase, the patient was stimulated verbally or with gentle tactile stimulation on the shoulder every $20 \mathrm{~s}$. From time zero, which was defined as a discontinuation of desflurane, the following variables were measured: time to the first response to the verbal command 'open your eyes', time to tracheal extubation, end-tidal desflurane concentration at the first response and extubation, and the grade of coughing episodes ( 0 : no cough; 1 : mild, single cough; 2 : moderate, more than 1 cough lasting $<5 \mathrm{~s}$; 3 : severe, sustained for more than $5 \mathrm{~s}$ ). These values were recorded by another observer blinded to the alfentanil dose. Extubation was performed when the patient could follow verbal commands and the tidal volume was sufficient. The mean arterial pressure (MAP) and heart rate (HR) were also recorded every $2 \mathrm{~min}$ from time 0 to $6 \mathrm{~min}$ after extubation. The presence of postoperative nausea and vomiting (PONV) and the modified Aldrete score [15] 30 min after admission to the post anesthesia care unit (PACU) were recorded.

Alfentanil dose was determined to be $16 \mu \mathrm{g} / \mathrm{kg}$ for the first patient, referring to a previous report [12]. Cough was defined as a sudden contraction of the abdomen. The success of suppressing cough during emergence was defined as grade 0 or 1 of any coughing episode. If cough suppression was successful, the alfentanil dose was decreased by $2 \mu \mathrm{g} / \mathrm{kg}$ in the consecutive patient. On the other hand, the dose was increased by $2 \mu \mathrm{g} / \mathrm{kg}$ in the consecutive patient if it failed.

Patient data was reported as the mean \pm standard deviation (SD). Statistical analysis was performed using the SPSS package (SPSS 13.0 for windows, SPSS Inc, Chicago, IL). According to Dixon's up-and-down method [16], the study continued until seven pairs of successful-failed suppressing emergence cough had occurred. The $50 \%$ effective dose $\left(\mathrm{ED}_{50}\right)$ of alfentanil for suppressing cough during emergence was defined as the mean of the median cross-over dose. The data was also subjected to isotonic regression estimators to calculate the $95 \%$ effective dose $\left(\mathrm{ED}_{95}\right)$ and the $95 \%$ confidence interval (CI). An adjusted response probability was easily calculated by the pooled adjacent-violators algorithm (PAVA) and the CI was estimated using a bootstrapping approach [17]. The hemodynamic changes during emergence were analyzed by repeated measures ANOVA. A P value $<0.05$ was considered significant.

\section{Results}

Twenty-nine patients were enrolled in this study when 
seven pairs of successful-failed suppressing emergence cough had occurred (Fig. 1). According to the success or failure in suppressing emergence cough, they were divided into a coughsuppressed group and a cough-unsuppressed group. Patient demographic data and operative characteristics in coughsuppressed group and cough-unsuppressed group were similar (Table 1). During the emergence phase, there were no significant differences in the response time, extubation time, and end tidal desflurane concentration at the response or extubation between the two groups. The two groups were also comparable with respect to the number of patients with PONV and the modified Aldrete score $30 \mathrm{~min}$ after admission to the PACU (Table 2). Hemodynamic changes during the emergence phase between the two groups were not significantly different. Within each group, the HR were similar compared to the baseline value but the MAP increased significantly after extubation compared to the baseline value (Fig. 2).

The $\mathrm{ED}_{50}$ of alfentanil for suppressing cough during emergence from desflurane anesthesia was $9.3 \pm 1.5 \mu \mathrm{g} / \mathrm{kg}$ according to Dixon's up-and-down method (Fig. 1). Isotonic regression,

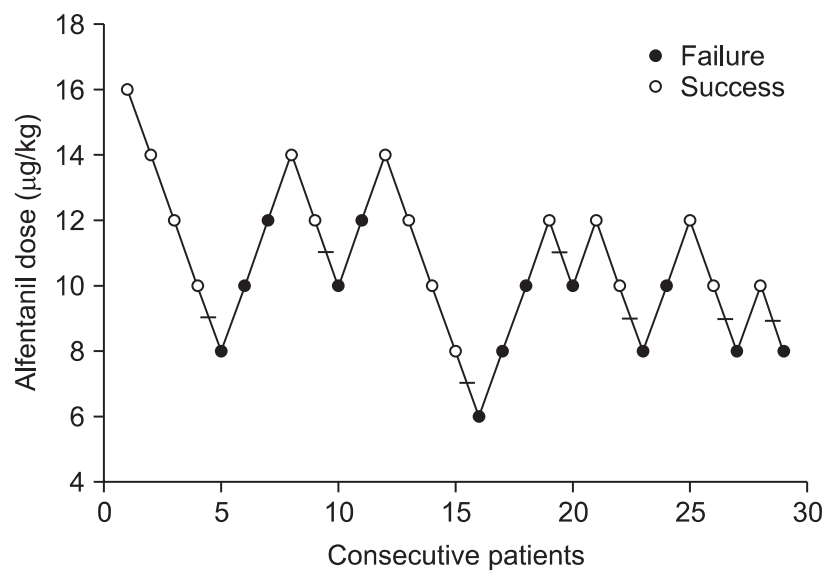

Fig. 1. Success or failure of suppressing coughing during emergence from desflurane anaesthesia on the determined alfentanil dose. The mean \pm SD of the median alfentanil dose of seven success-failure pairs is $9.3 \pm 1.5 \mu \mathrm{g} / \mathrm{kg}$ estimated from the Pooled-adjacent-violators algorithm (PAVA) response rate, revealed that an $\mathrm{ED}_{50}$ and $\mathrm{ED}_{95}$ of alfentanil were $10.0 \mu \mathrm{g} / \mathrm{kg}(95 \% \mathrm{CI} 6.8-13.2 \mu \mathrm{g} / \mathrm{kg})$ and $14.0 \mu \mathrm{g} / \mathrm{kg}(95 \% \mathrm{CI}$ $7.7-19.4 \mu \mathrm{g} / \mathrm{kg}$ ), respectively (Fig. 3).

\section{Discussion}

This is the first study on the dose-response of alfentanil for suppressing emergence cough. In this study, the $\mathrm{ED}_{95}$ of alfentanil for suppressing cough during emergence from desflurane anesthesia was $14.0 \mu \mathrm{g} / \mathrm{kg}$.

Most upper airway reflex responses including the cough reflex have been observed in humans anesthetized lightly with inhalational anesthetics $[18,19]$. During emergence from inhalational anesthesia, stimulation of the airway mucosa in the state of light anesthesia can cause cough responses, interfering with smooth emergence. Among these airway reflex responses, the cough reflex appears to be most vulnerable to the depressant effect of fentanyl [20]. Opioid agonists, such as fentanyl, are centrally acting antitussive agents [21]. Recent studies reported that the antitussive effects of opioids are

Table 1. Demographic Data and Surgical Characteristics

\begin{tabular}{lcc}
\hline & $\begin{array}{c}\text { Cough- } \\
\text { suppressed } \\
\text { patients }(\mathrm{n}=16)\end{array}$ & $\begin{array}{c}\text { Cough- } \\
\text { unsuppressed } \\
\text { patients }(\mathrm{n}=13)\end{array}$ \\
\hline Age (yr) & $31 \pm 14$ & $32 \pm 13$ \\
Gender (male/female) & $9 / 7$ & $8 / 5$ \\
Weight (kg) & $60 \pm 9$ & $62 \pm 8$ \\
ASA physical status (I/II) & $15 / 1$ & $11 / 2$ \\
History of smoking & 7 & 7 \\
Type of operation & 2 & 0 \\
Contouring surgery & 10 & 10 \\
Open reduction and internal & & 2 \\
$\quad$ fixation of mandible & 2 & 1 \\
Cyst enucleation & 2 & $124 \pm 25$ \\
Mass excision & $132 \pm 33$ & \\
Duration of operation (min) & &
\end{tabular}

Data is reported as the mean \pm SD or numbers. No significant difference between the two groups.

Table 2. Data on Coughing and Recovery Profile

\begin{tabular}{lcc}
\hline & Cough-suppressed patients (n=16) & Cough-unsuppressed patients ( $\mathrm{n}=13)$ \\
\hline Number of coughing episode & $0(0-2)$ & $2(1-3)$ \\
Response time (min) & $6.2 \pm 2.1$ & $6.7 \pm 1.5$ \\
End-tidal desflurane at first response (\%) & $0.67 \pm 0.17$ & $0.59 \pm 0.17$ \\
Extubation time (min) & $8.4 \pm 1.9$ & $8.4 \pm 1.4$ \\
End-tidal desflurane at extubation (\%) & $0.57 \pm 0.20$ & $0.53 \pm 0.17$ \\
Aldrete score 30 min after PACU admission & $9.6 \pm 0.5$ & $9.8 \pm 0.4$ \\
Total number of patients with PONV & 1 & 3
\end{tabular}

Data is reported as the mean \pm SD or numbers. Number of coughing episodes is shown as the median (range). No difference between two groups except for the number of coughing episodes. PACU: post anesthesia care unit, PONV: postoperative nausea and vomiting. 

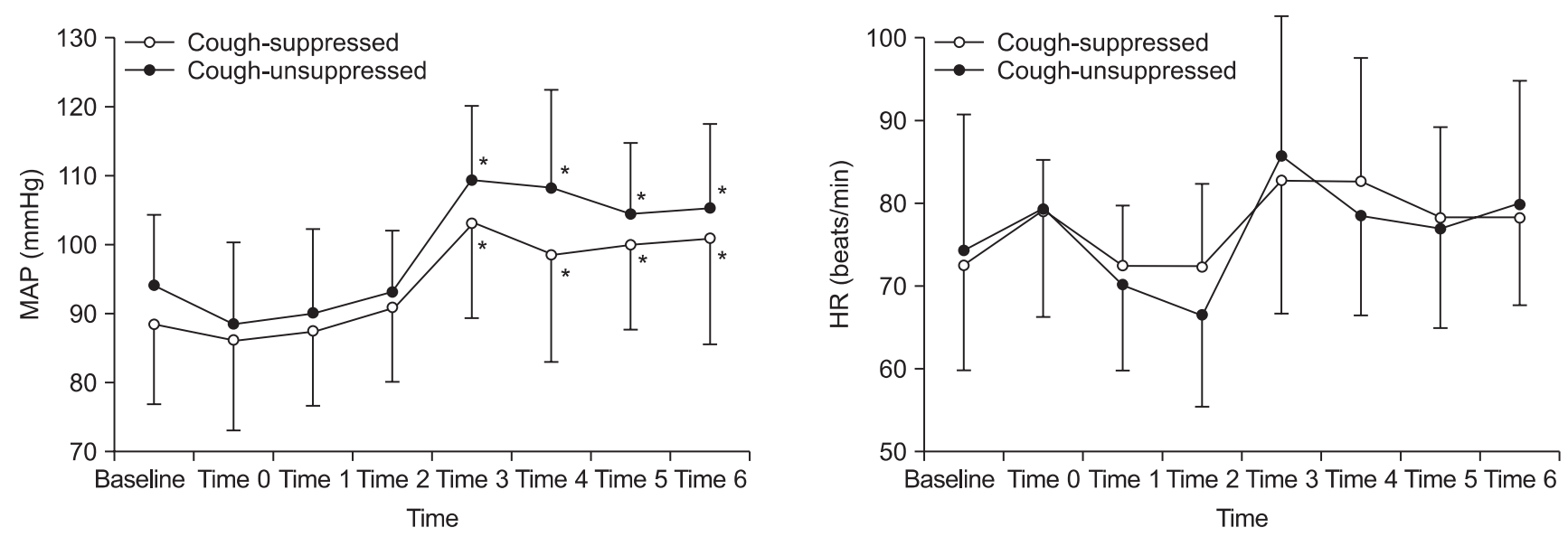

Fig. 2. Hemodynamic changes during the emergence phase. Time 0: at discontinuation of desflurane, time 1: 4 min before extubation, time 2: 2 min before extubation, time 3: at extubation, time 4: 2 min after extubation, time 5: 4 min after extubation, time 6: 6 min after extubation. There was no significant differences between the two groups. ${ }^{*} \mathrm{P}<0.05$ compared to the baseline.

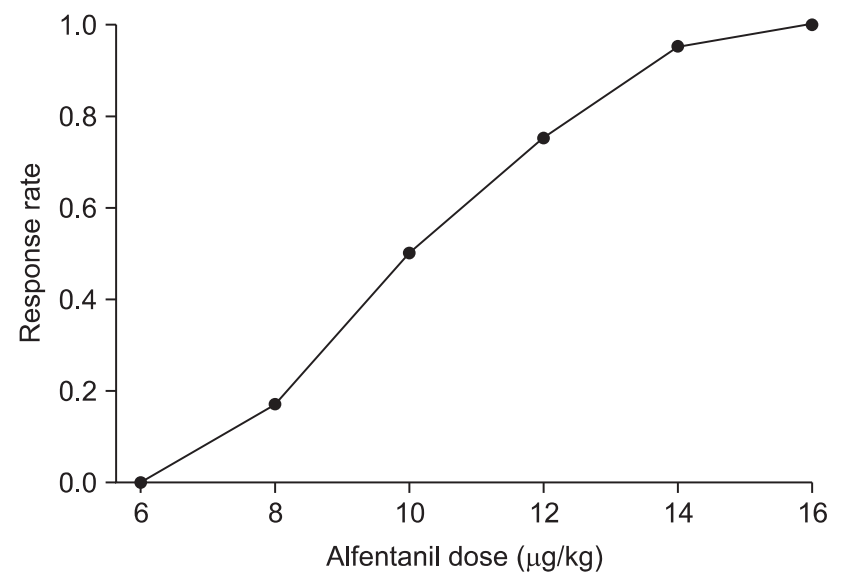

Fig. 3. Pooled-adjacent-violators algorithm (PAVA) response rate. The $\mathrm{ED}_{50}$ and $\mathrm{ED}_{95}(95 \%$ confidence interval), which were estimated from the PAVA response rate of the alfentanil dose for suppressing emergence cough from desflurane anesthesia, were $10.0 \mu \mathrm{g} / \mathrm{kg}(6.8-$ $13.2 \mu \mathrm{g} / \mathrm{kg})$ and $14.0 \mu \mathrm{g} / \mathrm{kg}(7.7-19.4 \mu \mathrm{g} / \mathrm{kg})$, respectively.

mediated predominantly by mu-and kappa-opioid receptors in the central nervous system [22,23].

Several studies reported that short-acting opioids, such as alfentanil and remifentanil, suppressed emergence cough induced by the endotracheal tube. The continuous infusion of low-dose remifentanil during emergence from isoflurane anesthesia reduced the incidence and severity of emergence cough [13]. Lee et al. [14] found that the $\mathrm{EC}_{95}$ of the effect site concentration of remifentanil to prevent coughing at emergence from propofol-remifentanil anesthesia was $2.14 \mathrm{ng} / \mathrm{ml}$. However, a bolus of $1 \mu \mathrm{g} / \mathrm{kg}$ remifentanil at the end of surgery did not reduce the incidence of cough during emergence from isoflurane anesthesia [24]. On the other hand, a single bolus injection of alfentanil ( $15 \mu \mathrm{g} / \mathrm{kg})$ during emergence decreased the incidence of emergence cough from $82 \%$ to $6 \%$ [12]. For this reason, alfentanil may be more suitable for single bolus administration to decrease emergence cough. Alfentanil bolus administration is a simple method compared to remifentanil continuous infusion. However, no dose-finding study on the clinical effective dose of alfentanil to suppress emergence cough have been conducted. Therefore, the clinically effective single dose of alfentanil for suppressing emergence cough was determined using Dixon's up-and-down method in this study.

A single bolus administration of alfentanil at the end of surgery did not prolong the extubation time compared to the control group [12]. Similarly, the extubation time in this study after the administration of alfentanil was $<10 \mathrm{~min}$ in both groups, which is a clinically acceptable emergence time. In the hemodynamic changes during emergence, HR was relatively stable but the MAP increased significantly after extubation in both groups. These results were on various doses of alfentanil. Therefore, more studies of the recovery profile or hemodynamic changes on this optimal alfentanil dose are required.

These results have some limitations when applied to clinical practice. The desflurane used in this study has a direct effect on pungency and airway irritability [25]. This property of desflurane can affect the effective clinical dose of alfentanil for suppressing cough during emergence. The optimal dose of alfentanil may be different in preventing emergence cough for other anesthetics, such as sevoflurane or propofol. In addition, the criterion of success in suppressing emergence cough was not absence of cough. Therefore, the alfentanil dose proposed in this study may not be sufficient for situations requiring absolute smooth emergence.

In conclusion, the $95 \%$ effective dose $\left(\mathrm{ED}_{95}\right)$ of alfentanil for suppressing cough during emergence from desflurane anesthesia is $14 \mu \mathrm{g} / \mathrm{kg}$ using Dixon's up-and-down method and 
isotonic regression. A single bolus administration of alfentanil during emergence from desflurane anesthesia is useful for suppressing emergence cough.

\section{References}

1. Fagan C, Frizelle HP, Laffey J, Hannon V, Carey M. The effects of intracuff lidocaine on endotracheal tube induced emergence phenomena after general anesthesia. Anesth Analg 2000; 91: 201-5.

2. Gonzalez RM, Bjerke RJ, Drobycki T, Stapelfeldt WH, Green JM, Janowitz MJ, et al. Prevention of endotracheal tube-induced coughing during emergence from general anesthesia. Anesth Analg 1994; 79:792-5.

3. Kim ES, Bishop MJ. Cough during emergence from isoflurane anesthesia. Anesth Analg 1998; 87: 1170-4.

4. Leech P, Barker J, Fitch W. Proceedings: changes in intracranial pressure and systemic arterial pressure during the termination of anaesthesia. Br J Anaesth 1974; 46:315-6.

5. Holden R, Morsman CD, Butler J, Clark GS, Hughes DS, Bacon PJ. Intra-ocular pressure changes using the laryngeal mask airway and tracheal tube. Anaesthesia 1991; 46: 922-4.

6. Bidwai AV, Bidwai VA, Rogers CR, Stanley TH. Blood-pressure and pulse-rate responses to endotracheal extubation with and without prior injection of lidocaine. Anesthesiology 1979; 51: 171-3.

7. Neelakanta G, Miller J. Minimum alveolar concentration of isoflurane for tracheal extubation in deeply anesthetized children. Anesthesiology 1994; 80: 811-3.

8. Koga K, Asai T, Vaughan RS, Latto IP. Respiratory complications associated with tracheal extubation. Timing of tracheal extubation and use of the laryngeal mask during emergence from anaesthesia. Anaesthesia 1998; 53: 540-4.

9. Minogue SC, Ralph J, Lampa MJ. Laryngotracheal topicalization with lidocaine before intubation decreases the incidence of coughing on emergence from general anaesthesia. Anesth Analg 2004; 99: 1253-7.

10. Fagan C, Frizelle HP, Laffey J, Hannon V, Carey M. The effects of intracuff lidocaine on endotracheal-tube-induced emergence phenomena after general anaesthesia. Anesth Analg 2000; 91: 201-5.

11. Guler G, Akin A, Tosun Z, Eskitascoglu E, Mizrak A, Boyaci A. Single-dose dexmedetomidine attenuates airway and circulatory reflexes during extubation. Acta Anaesthesiol Scand 2005; 49: 108891.
12. Mendel P, Fredman B, White PF. Alfentanil suppresses coughing and agitation during emergence from isoflurane anesthesia. J Clin Anesth 1995; 7: 114-8.

13. Aouad MT, Al-Alami AA, Nasr VG, Souki FG, Zbeidy RA, SiddikSayyid SM. The effect of low-dose remifentanil on responses to the endotracheal tube during emergence from general anesthesia. Anesth Analg 2009; 108: 1157-60.

14. Lee B, Lee JR, Na S. Targeting smooth emergence: the effect site concentration of remifentanil for preventing cough during emergence during propofol-remifentanil anaesthesia for thyroid surgery. Br J Anaesth 2009; 102: 775-8.

15. Aldrete JA. The post-anesthesia recovery score revisited. J Clin Anesth 1995; 7: 89-91.

16. Dixon WJ. Staircase bioassay: the up-and-down method. Neurosic Biobehav Rev 1991; 15: 47-50.

17. Pace NL, Stylianou MP. Advances in and limitation of up-anddown methodology: a précis of clinical use, study design, and dose estimation in anesthesia research. Anesthesiology 2007; 107: 14452.

18. Nishino T, Hiraga K, Mizuguchi T, Honda Y. Respiratory reflex responses to stimulation of tracheal mucosa in enflurane-anesthetized humans. J Appl Physiol 1988; 65: 1069-74.

19. Nishino T, Kochi T, Ishii M. Differences in respiratory reflex responses from the larynx, trachea, and bronchi in anesthetized female subjects. Anesthesiology 1996; 84: 70-4.

20. Tagaito $Y$, Isono S, Nishino T. Upper airway reflexes during a combination of propofol and fentanyl anesthesia. Anesthesiology 1998; 88: 1459-66.

21. Miller RD. Anesthesia. 4th ed. New York, Churchill Livingstone. 1994, pp 291-388.

22. Kamei J, Tanihara H, Kasuya Y. Antitussive effects of two specific kappa-opioid agonists, U-50, 488H and U-62, 066E, in rats. Eur J Pharmacol 1990; 187: 281-6.

23. Kamei J, Tanihara H, Kasuya Y. Modulation of mu- mediated antitussive activity in rats by a delta agonist. Eur J Pharmacol 1991; 203: 153-6.

24. Shajar MA, Thompson JP, Hall AP, Leslie NA, Fox AJ. Effect of a remifentanil bolus dose on the cardiovascular response to emergence from anaesthesia and tracheal extubation. Br J Anaesth 1999; 83: 654-6.

25. Barash PG, Cullen BF, Stoelting RK, Cahalan MK, Stock MC. Clinical anesthesia. 6th ed. Philadelphia, Lippincott Williams\&Wilkins. 2009, p 434. 